\title{
The effect of disbudding age on healing and pain sensitivity in dairy calves
}

\author{
Sarah J. J. Adcock and Cassandra B. Tucker ${ }^{1}$ \\ Center for Animal Welfare, Department of Animal Science, University of California, Davis 95616
}

\begin{abstract}
Hot-iron disbudding, a husbandry procedure performed in dairy calves in which horn bud growth is prevented through tissue cauterization, produces severe burns. Little is known about how long pain persists following disbudding or factors, such as age at the time of disbudding, that may influence animal welfare outcomes. Our objectives were (1) to evaluate whether disbudding age mediates healing, pain sensitivity, and weight gain in calves disbudded near birth $(3 \mathrm{~d})$ compared with at a later age $(35 \mathrm{~d})$; and $(2)$ to examine how long wounds are sensitive during healing. Fortyeight calves were disbudded or sham-disbudded at 3 or $35 \mathrm{~d}$ of age $(\mathrm{n}=12 /$ treatment $)$. We assessed pain sensitivity with a pressure algometer on d 3 and 7 after disbudding and then weekly thereafter until the wound had re-epithelialized. Sensitivity was measured at the lateral and caudal edges of each wound, as well as on the rump to test for systemic changes in sensory function. We evaluated healing by scoring the presence of 7 tissue types in the wound bed: attached necrotic tissue, detached necrotic tissue, burns outside the necrotic ring, exudate, granulation, crust, and epithelium. Tissue scores, surface temperature, and girth circumference as an estimate of weight gain were measured twice weekly until the wound had re-epithelialized. Disbudded tissue was more sensitive than nondisbudded tissue for at least $3 \mathrm{wk}$, after which time the sham calves were removed from the study to be disbudded. Wounds took $62 \pm 10 \mathrm{~d}($ mean $\pm \mathrm{SD})$ to re-epithelialize and were more painful than new epithelium throughout this time, regardless of whether the procedure occurred at 3 or $35 \mathrm{~d}$ of age. The surface temperature of disbudding wounds did not differ from that of non-disbudded tissue nor did disbudding affect weight gain at either age. Age at the time of disbudding did not affect latency to re-epithelialize or wound sensitivity. However, rump sensitivity was greater in calves disbudded at 3 versus
\end{abstract}

Received April 27, 2018

Accepted June 29, 2018.

${ }^{1}$ Corresponding author: cbtucker@ucdavis.edu
$35 \mathrm{~d}$ of age on d 28, 42, and 56 after disbudding, in agreement with other studies showing increased pain sensitivity when painful procedures are performed at an early age. In conclusion, wounds remain painful throughout healing, raising animal welfare concerns about hot-iron disbudding. Performing the procedure near birth does not improve welfare outcomes; rather, some evidence suggests it may produce a generalized long-term increase in pain sensitivity.

Key words: animal welfare, dehorning, mechanical nociceptive threshold, thermal burn

\section{INTRODUCTION}

Hot-iron disbudding, a husbandry procedure in which horn bud growth is prevented through tissue cauterization, is commonly performed in dairy calves between 0 and 2 mo of age (USDA, 2018). Hot-iron disbudding is painful (Stock et al., 2013). Postoperative pain is associated with specific behaviors (e.g., ear flicks, head shakes, and head rubbing) and physiological changes (e.g., plasma cortisol responses, increased heart rate), which are dampened by administration of local anesthetics and nonsteroidal anti-inflammatory drugs (Stock et al., 2013). In addition to acute pain, injury can cause prolonged inflammation that can persist until the wound is healed, which can take months for burns such as hot-iron brands in cattle (Tucker et al., 2014b). A consistent feature of inflammation is an increased pain response to stimulation around the wound. It is unknown how long wounds remain sensitive following disbudding, as studies have largely focused on the first few hours or days following the procedure (Adcock and Tucker, 2018).

Disbudding at or near birth may present a practical strategy for mitigating pain; less tissue may be damaged if a smaller iron tip is used and, as a result, the wound may heal faster. Smaller wounds may also offer economic benefits such as a faster recovery of weight gain due to relatively lower metabolic demands for wound repair (Newsome et al., 1973; Demling, 2009). Although these assumptions have not been tested, several organizations recommend that the procedure be performed at the youngest practical age, which is in- 
creasingly interpreted as less than 1 wk of age (American Association of Bovine Practitioners, 2014; National Milk Producers Federation, 2016; American Veterinary Medical Association, 2018). However, many regulatory organizations permit painful procedures without pharmacological analgesia in animals under a certain age, despite a notable lack of empirical evidence to support this allowance. For example, the European Convention, which applies to 47 countries, recommends that pain relief be used when disbudding calves over $4 \mathrm{wk}$ of age (Council of Europe, 1988). Not only is there ample evidence that neonatal ungulates feel pain (e.g., Boesch et al., 2008; Guesgen et al., 2011; Caray et al., 2015), but pain may be experienced more intensely at younger ages due to the rapid activation of awareness soon after birth (Mellor and Stafford, 2004, but see Johnson et al., 2005, 2009; Dockweiler et al., 2013). In addition, painful experiences in neonates can alter development of neural pain pathways, leading to a systemic increase in pain sensitivity that can persist into adulthood in both altricial (humans: Taddio et al., 1997; rodents: Beggs et al., 2012) and precocial species (sheep: McCracken et al., 2010).

Our objectives were (1) to evaluate whether disbudding age mediates healing time and pain sensitivity in calves disbudded near birth $(3 \mathrm{~d})$ compared with a later age $(35 \mathrm{~d})$; and $(2)$ to examine when and for how long wounds are sensitive during healing. We predicted that (1) disbudding near birth will hasten wound re-epithelialization, but will lead to increased pain sensitivity compared with calves disbudded at $35 \mathrm{~d}$ of age; and (2) disbudded calves will be more sensitive to stimulation around the wound than sham-disbudded calves through the healing process.

\section{MATERIALS AND METHODS}

We carried out this study from July to December 2016 at the University of California Davis Dairy Facility. The University of California Davis Institutional Animal Care and Use Committee approved all procedures and daily husbandry practices.

\section{Animals and Housing}

At birth, 40 Holstein and 8 Jersey heifer calves were housed individually in outdoor plastic hutches $(2.0 \times$ $1.5 \mathrm{~m})$ with an attached wire-fenced pen $(2.0 \times 1.5$ $\times 0.9 \mathrm{~m}$; length $\times$ width $\times$ height $)$. The enclosures were bedded with rice hulls $\sim 15$ to $20 \mathrm{~cm}$ deep and spaced $0.5 \mathrm{~m}$ apart, allowing visual and auditory contact between calves. Calves were ear-tagged at 1 to $2 \mathrm{~d}$ of age. Feeding followed the farm's standard operating procedure (Supplemental Figure S1; https://doi.org/ 10.3168/jds.2018-14987). Jerseys and Holsteins were bottle-fed 1.4 and $1.9 \mathrm{~L}$, respectively, of milk replacer (26\% CP, $16 \%$ fat, $15 \%$ total solids; Calva Products Inc., Acampo, CA) twice daily, and had ad libitum access to water and starter $(18.3 \% \mathrm{CP}, 2.8 \%$ fat, $4 \%$ crude fat; Associated Feed \& Supply Co., Turlock, CA). Feeding times were 0930 and $1630 \mathrm{~h}$. The amount at each feeding was increased by $0.5 \mathrm{~L}$ at $14 \mathrm{~d}$ of age and again at $24 \mathrm{~d}$ of age. For Jerseys only, feeding was increased by $0.5 \mathrm{~L}$ again at $31 \mathrm{~d}$ of age. Calves were switched to bucket feeding at 35 to $38 \mathrm{~d}$ of age and a dry TMR was introduced. Calves were fully weaned at $60 \mathrm{~d}$ of age. At $70 \mathrm{~d}$ of age, calves moved to an outdoor group pen where they were fed a dry TMR twice daily. We note that although this plane of nutrition is conventional practice, it is below that needed to meet calves' nutritional requirements for maintenance, growth, and development (Khan et al., 2011a).

\section{Treatments}

We assigned all female calves born on the farm between May 30 and September 28 to a $2 \times 2$ factorial arrangement $(\mathrm{n}=12$ /treatment): disbudding or shamdisbudding at 3 or $35 \mathrm{~d}$ of age. Experiments were conducted in 12 replicates with each treatment represented (4 calves/replicate). Calves were allocated to replicates based on birth order. Calves were randomly assigned treatments using computer-generated random numbers but, within this approach, were also balanced by breed. At the start of the experiment, sham and disbudded calves had similar BW within each age group (mean \pm SD: 35-d-old disbudding: $52 \pm 9 \mathrm{~kg}$; 35-d-old sham: 52 $\pm 6 \mathrm{~kg}$; 3-d-old disbudding: $39 \pm 5 \mathrm{~kg}$; 3 -d-old sham: $37 \pm 6 \mathrm{~kg})$.

On the day of disbudding, the calf was restrained with a head device in the home pen and $5 \mathrm{~mL}$ of $2 \%$ lidocaine hydrochloride was injected subcutaneously on each side of the head with a 20 -gauge $\times 25$-mm needle to achieve a cornual nerve block. Anesthesia was checked $10 \mathrm{~min}$ after administration with a prick test around the base of each horn bud. If a behavioral response occurred, an additional $2 \mathrm{~mL}$ was given, which always sufficed. A 5- or $7-\mathrm{cm}^{2}$ square patch of hair was clipped with an electric razor fitted with a size 40 blade on each side of the head to localize the horn buds for 3- and 35-d-old calves, respectively. An electric cautery iron (Rhinehart X50, Rhinehart Development Corp., Spencerville, IN) was applied to each horn bud until a uniform copper ring formed (mean duration of application/bud \pm SD: 35-d-old disbudding: $18 \pm 4 \mathrm{~s}$; 3-d-old disbudding: $18 \pm$ 5 s; 35-d-old sham: $12 \pm 1 \mathrm{~s} ; 3$-d-old sham: $12 \pm 2 \mathrm{~s}$ ). The iron was fitted with a $0.6-$ or $1.3-\mathrm{cm}$ tip for 3 - and 35-d-old calves, respectively. An infrared thermometer 
(model 42412; Extech Instruments Corp., Nashua, NH) was used to measure the temperature of the iron immediately before disbudding (mean $\pm \mathrm{SD}: 467 \pm 22^{\circ} \mathrm{C}$ ). After disbudding, the calf received a gelatin capsule (1/8 oz., Torpac, Fairfield, NJ) containing $7.5 \mathrm{mg}$ of meloxicam tablets at a dose of $1 \mathrm{mg} / \mathrm{kg}$. S. J. J. A. performed all disbudding procedures.

Sham-disbudded calves were handled in a similar manner after lidocaine administration, with the exception that the iron was ambient temperature and the gelatin capsule was empty. Sham calves did not receive meloxicam because nontherapeutic off-label use of this drug is prohibited under the Animal Medicinal Drug Use Clarification Act (US Food and Drug Administration, 1994). Sham calves were removed from the trial at $58 \mathrm{~d}$ of age and disbudded to avoid the ethical concerns associated with using more invasive techniques (e.g., scoop dehorning) that are needed to prevent horn growth after 8 wk of age.

\section{Data Collection}

Healing Progress. We took digital photographs of the wound twice weekly with a DSLR camera (D60; Nikon Corp., Tokyo, Japan) until the wound was completely re-epithelialized (12-26 photos/wound). Photos were taken $15 \mathrm{~cm}$ from the wound and the calf was shaded by an umbrella at the time of the photograph. One person, blind to calf age, scored the photos for tissues present in the wound bed $(0 / 1$ scoring; Figure 1 ; intraobserver reliability: Cohen's $\kappa>0.90)$. Images in which the wound was obscured by hair were excluded ( $<1 \%$ of photos).

Pain Sensitivity. We assessed tissue sensitivity with a digital algometer (ProdPlus; TopCat Metrology Ltd., Little Downham, UK) fitted with a 4-mmdiameter round rubber tip. Calves were tested on $\mathrm{d}$ 3 and 7 after disbudding and then weekly thereafter until re-epithelialization was complete. Tests occurred at the lateral and caudal edges of each wound or the equivalent location on sham calves (Figure 2a). In addition, we measured sensitivity of a shaved patch on the rump, between the sacral vertebrae and the hip joint, to determine whether disbudding increased sensitivity at a site distal to the injury (Figure $2 \mathrm{~b}$ ). The side of the rump (left vs. right) that was tested was balanced by treatment. The order of test sites was randomized without replacement within and between replicates of 4 calves using computer-generated random numbers, with the exception that the rump site was always tested last. Within this approach, test site order was also balanced across treatments. To ensure force was applied at a consistent rate, personnel operating the algometer were trained to meet a set of criteria before performing the tests (Supplemental Table S1; https://doi.org/10.3168/ jds.2018-14987). Due to the nature of the tests, the operator of the algometer was not blind to treatment.

During testing, the calf was restrained in the head device in her home pen and blindfolded. An operator touched the tip of the algometer to the calf's skin (using $<0.01 \mathrm{~N}$ of force) and held it there until the calf's head was still and not pulling back against the restraint (Supplemental Video S1; https://doi.org/10.3168/jds .2018-14987). Force was applied at a consistent rate (mean \pm SD: $0.27 \pm 0.11 \mathrm{~N} / \mathrm{s}$ ) until the calf moved her head away from the algometer (wound sites), the hind leg on the side being tested shifted (rump site), or a maximum $10 \mathrm{~N}$ of force was reached. We used video (Panasonic HC-V550, Kadoma, Japan) to quantify the rate that force increased in each test (4\% of videos missing overall). If force was not consistent; that is, force was applied at a rate $<0.1$ or $>0.6 \mathrm{~N} / \mathrm{s}$, then these data were excluded ( $7 \%$ of videos). The test was repeated if any interruptions occurred (loud noise; the animal urinated or defecated; fly landed on head or rump). If a test was interrupted 3 times, it was abandoned ( $2 \%$ of tests).

Infrared Thermography. We used a thermal camera (RAZ-IR Nano; Sierra Pacific Innovations, Las Vegas, NV) to measure wound surface temperature twice a week for 3 wk. Photos were collected out of direct sunlight using an umbrella placed over the calf's pen. To standardize the image area, we placed a cardboard frame around the shaved patch of skin, with the wound or horn bud at the center. The frame measured $5 \times 5$ or $7 \times 7 \mathrm{~cm}$ for calves disbudded at 3 or $35 \mathrm{~d}$ of age, respectively. The average temperature of the shaved square area was determined using image analysis software (IR Analyzer, Sierra Pacific Innovations; interobserver reliability: intraclass correlation coefficient $=0.99$ ). Images without the cardboard frame were excluded (20\% of photos).

Weight. Calves were weighed the day of disbudding and a week later. Two calves from the 35-d-old group were not weighed a week after disbudding because they were too large to transport to the scale. In addition, we measured girth circumference twice weekly until the wound had re-epithelialized (interobserver reliability: intraclass correlation coefficient $=0.97)$. Then, ADG for weight and girth circumference were calculated for each calf using the difference from the baseline measurement before the procedure and dividing by the number of days since this value was taken.

\section{Statistical Analysis}

We tested the effect of disbudding age on latencies for the necrotic tissue to detach and for a complete 


\begin{tabular}{|c|c|c|}
\hline Example & Tissue & Description \\
\hline & $\begin{array}{l}\text { Attached } \\
\text { necrotic tissue }\end{array}$ & $\begin{array}{l}\text { The edges of the copper ring are not separated from the } \\
\text { scalp }\end{array}$ \\
\hline & $\begin{array}{l}\text { Burned tissue } \\
\text { outside the ring }\end{array}$ & $\begin{array}{l}\text { Hairless patch(es) around the outside of copper ring; only } \\
\text { observed when attached necrotic tissue is present }\end{array}$ \\
\hline & $\begin{array}{l}\text { Detached } \\
\text { necrotic tissue }\end{array}$ & $\begin{array}{l}\text { The edges outside the copper ring have started to separate } \\
\text { from the scalp }\end{array}$ \\
\hline & Exudate & $\begin{array}{l}\text { Fresh blood; can be moist or freshly dried (discoloration } \\
\text { has not yet occurred) }\end{array}$ \\
\hline & Granulation & $\begin{array}{l}\text { Light red/dark pink, opaque, bumpy tissue; may be } \\
\text { observed underneath detached necrotic tissue }\end{array}$ \\
\hline & Crust & $\begin{array}{l}\text { Dried exudate; may be present underneath detached } \\
\text { necrotic tissue; isolated specks (pencil-tip size) of dried } \\
\text { blood are not counted }\end{array}$ \\
\hline & Epithelium & $\begin{array}{l}\text { Layer of translucent skin is present; the other tissues types } \\
\text { are absent }\end{array}$ \\
\hline
\end{tabular}

Figure 1. The system used to evaluate tissue types in disbudding wounds. Color version available online. 
epithelial layer to form using linear mixed models with calf included as a random effect.

We used linear mixed models to assess the effect of disbudding on pain sensitivity of the head and rump, surface temperature, and girth circumference ADG during the following $3 \mathrm{wk}$, after which time the calves sham-disbudded at $35 \mathrm{~d}$ of age were removed from the trial. Procedure (disbudded vs. sham), day relative to the procedure, age at the time of the procedure $(3 \mathrm{vs}$. $35 \mathrm{~d}$ ), and their 2-way interactions were included as fixed effects, and calf as a random effect, in the models of pain sensitivity and girth circumference ADG. Age at the time of the procedure was excluded from the model of surface temperature because of confounding factors (i.e., differences in surface area between age groups). We included side (left vs. right), location (lateral vs. caudal), test order (1 to 4 ), and their interactions with procedure as fixed effects in the model of head sensitivity. A linear model was used to test an interaction effect of disbudding and age at the time of the procedure on ADG $(\mathrm{kg})$ in the week following disbudding.

In disbudded animals only, the effect of disbudding age on pain sensitivity of the wounds and rump, as well as on girth circumference ADG, was analyzed over a 9-wk healing period, after which time the majority of wounds had re-epithelialized. The models included the interaction between disbudding age and day relative to disbudding as a fixed effect, and calf as a random effect. A linear model was used to test the effect of disbudding age on final girth circumference in 9-wk-old calves.

We compared the sensitivity of each damaged tissue type to that of new epithelium using linear mixed models, with calf fitted as a random effect. Sensitivity thresholds for each calf were averaged over all test days by tissue type, resulting in 1 data point per tissue per calf. Sample sizes for each tissue type differed because some tissues were not observed in all calves. If multiple tissues were present in a single wound on the same test day, the sensitivity thresholds for that wound were included in each tissue analysis.

All models were fit using the REML method implemented in the "nlme" (Pinheiro et al., 2017) package in $\mathrm{R}$ (version 3.4.1; R Core Team, 2017). Degrees of freedom were estimated using the containment method. We visually inspected residuals versus fit plots and quantile-quantile (Q-Q) plots to confirm homogeneity of variance and normality, respectively, for all models. A first-order autoregressive correlation structure was applied to all models that included day relative to disbudding as a fixed effect. This correlation structure was selected based on the lowest Akaike information criterion value. Least squares means and standard errors are reported, unless noted otherwise. If interaction effects were identified in any of the models $(P<0.09)$, we performed pairwise comparisons using Tukey's method with the "lsmeans" package (Lenth, 2016).

\section{RESULTS}

\section{Healing}

Wounds took $62 \pm 10 \mathrm{~d}$ (mean $\pm \mathrm{SD}$; range: 42-91 d) to re-epithelialize (Figure 3 ). Age at the time of disbudding did not affect latency to re-epithelialize $(3 \mathrm{~d}: 60 \pm$ 2 d; 35 d: $64 \pm 2$ d; $\left.F_{1,22}=1.15, P=0.296\right)$. However,
A

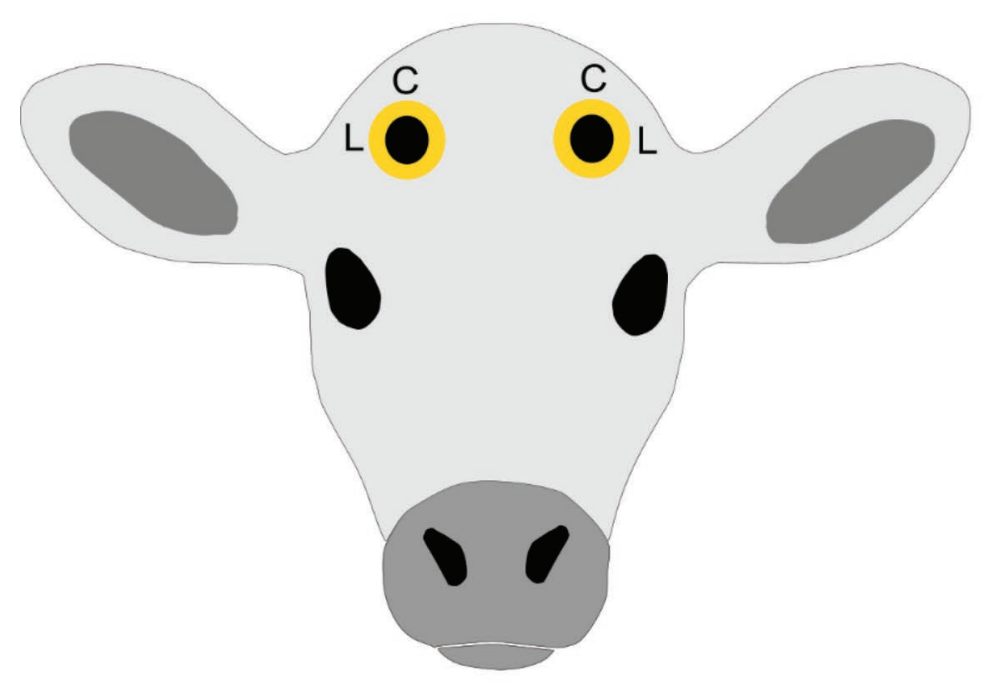

B

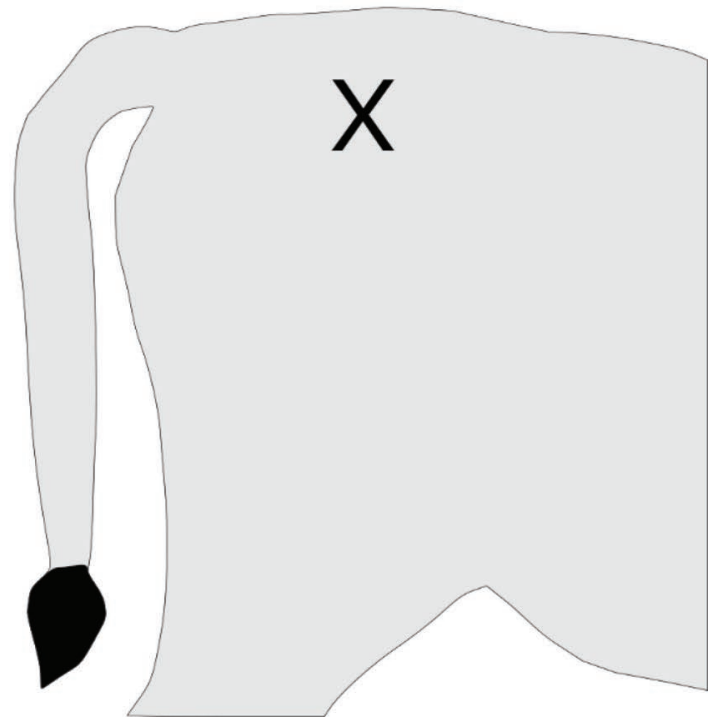

Figure 2. Pressure algometry sites on the edge of the wound or horn bud (A) and the rump (B). L = lateral; C = caudal; X = rump site. Illustration by Jason Miszaniec, University of California, Davis. Color version available online. 


\section{Week 1}

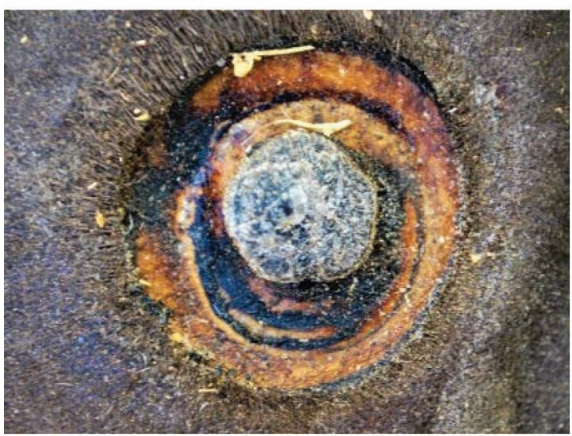

Week 4

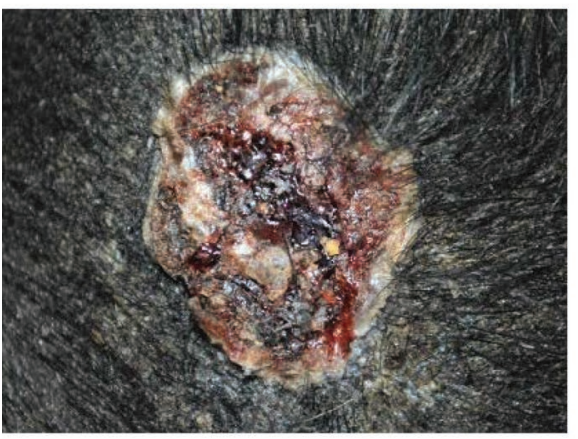

Week 7

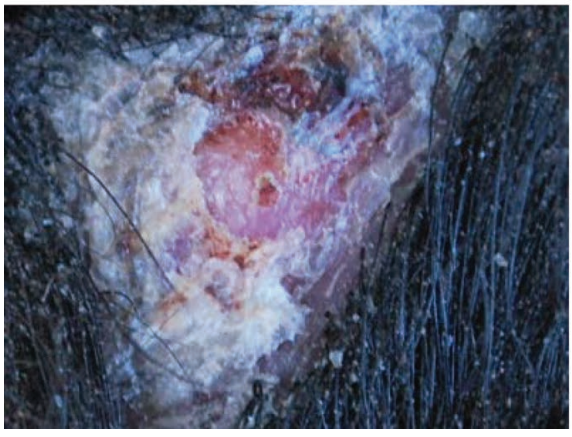

Week 2

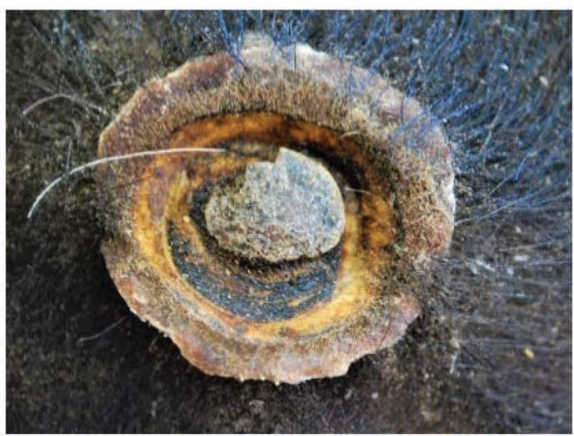

Week 5

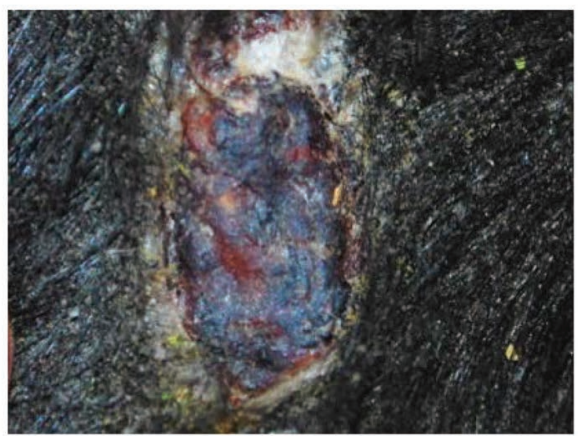

Week 8

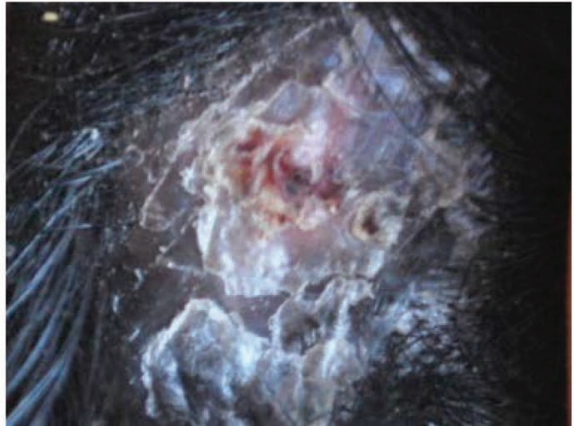

Week 3

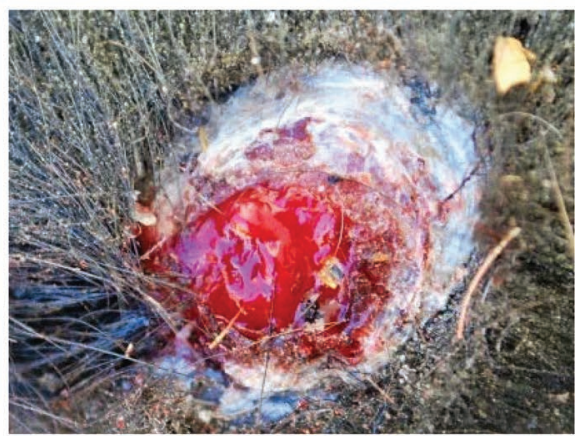

Week 6

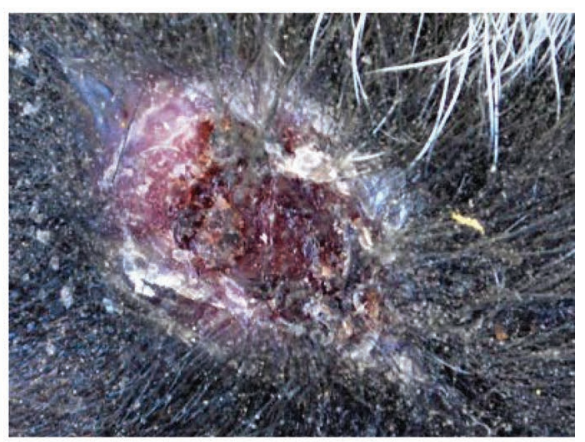

Week 9

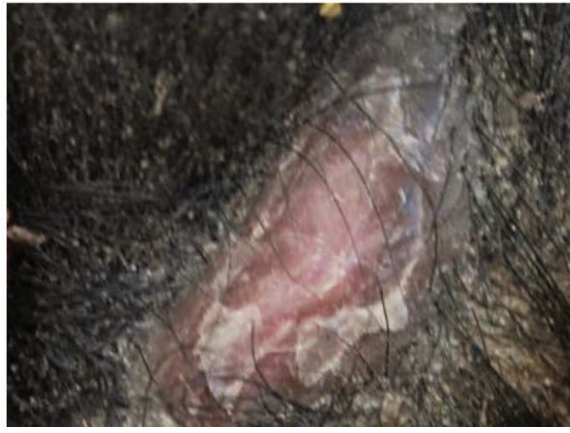

Figure 3. Healing progression of disbudding wounds over 9 wk. The necrotic tissue present immediately after disbudding begins to detach around wk 2, falling off completely by wk 3 . Over the next several weeks, the wound is rebuilt with granulation tissue and contracts toward the center. Concurrently, epithelial cells migrate across the wound bed until the wound is fully covered around wk 9 . Color version available online.

necrotic tissue took longer to detach in 3 -d-old calves compared with those disbudded at $35 \mathrm{~d}$ of age $(3 \mathrm{~d}: 26$ $\left.\pm 1 \mathrm{~d} ; 35 \mathrm{~d}: 23 \pm 1 \mathrm{~d} ; F_{1,22}=7.36, P=0.013\right)$. Figure 4 shows when different tissues were present during the healing period.

\section{Pain Sensitivity}

Disbudding wounds were more painful than nondisbudded tissue for at least $3 \mathrm{wk}$, although these differences became less pronounced over time (procedure $x$ time since disbudding: $F_{3,628}=3.57 ; P=0.014$; Figure
5). Older calves were more sensitive to pressure applied to their head over the $3 \mathrm{wk}$ following the procedure, regardless of whether they were disbudded $(3 \mathrm{~d}: 1.85 \pm$ $0.08 \mathrm{~N} ; 35 \mathrm{~d}: 1.51 \pm 0.08 \mathrm{~N} ; F_{1,44}=8.37, P=0.006$; procedure $\times$ disbudding age: $F_{1,44}=0.18, P=0.255$; Figure 5). Side, location, and test order did not affect sensitivity $\left(F_{1,628} \leq 0.74 ; P \geq 0.389\right)$.

When analyzing only disbudded animals over a 9-wk period, calves disbudded at an older age were more sensitive than younger calves on d 3 only (time since disbudding $\times$ disbudding age: $F_{9,735}=2.11 ; P=0.027$; Figure 6 ). All tissues present during wound healing were 


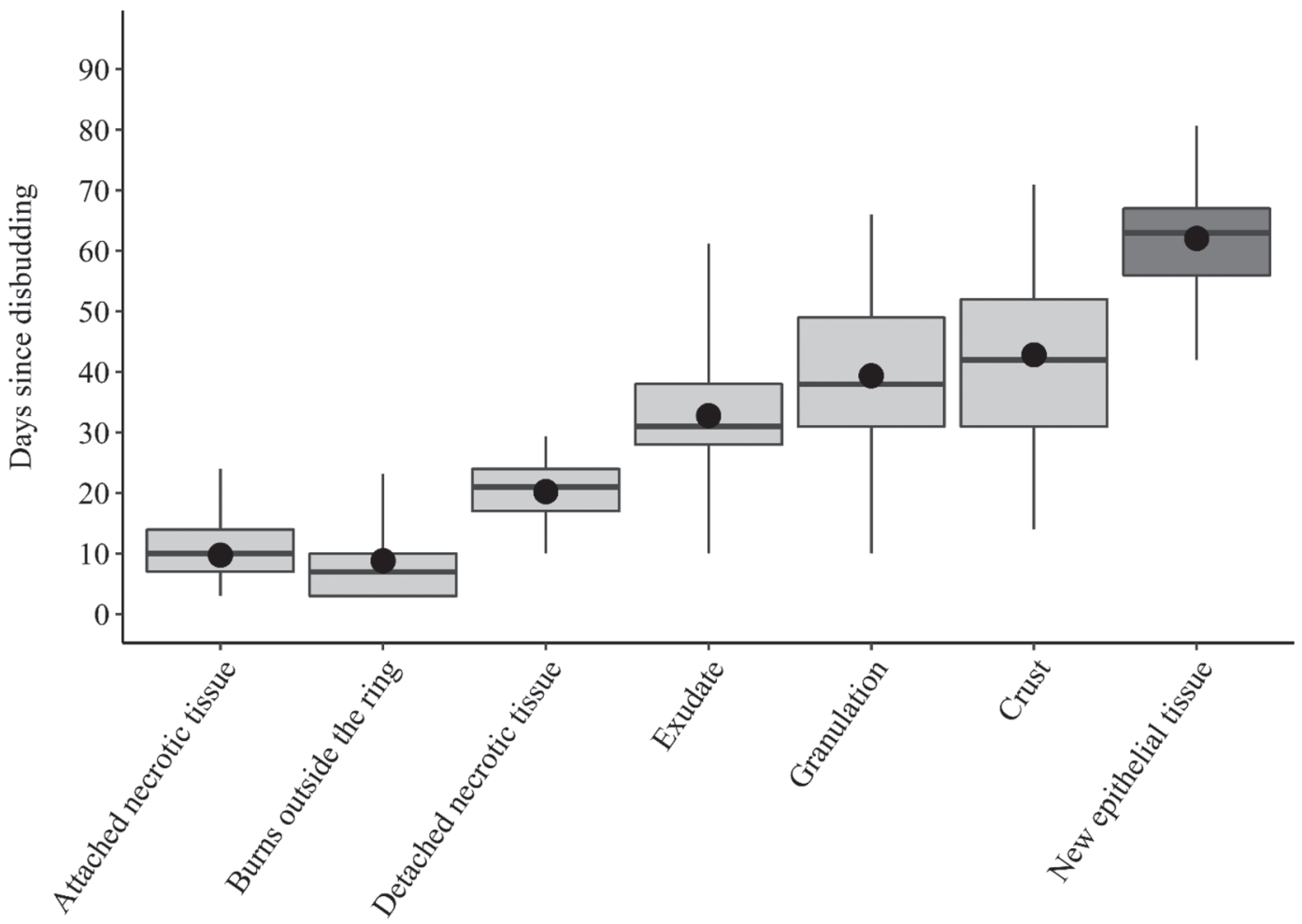

Figure 4. Days each tissue was observed relative to disbudding. Whiskers indicate the 2nd and 98th percentiles and circles indicate arithmetic means. The top and bottom of the boxes indicate the 75 th and 25th quartiles, respectively.

more sensitive than new epithelium (attached necrotic tissue: $F_{1,21}=28.01$; burns outside the ring: $F_{1,18}=$ 31.86; detached necrotic tissue: $F_{1,20}=43.08$; exudate: $F_{1,16}=16.94$; granulation: $F_{1,21}=21.08$; crust: $F_{1,21}=$ 23.38; $P<0.001$; Figure 7).

Neither the procedure, the day relative to procedure, age at the time of the procedure, nor their 2-way interactions predicted pain sensitivity at a site distal to the injury (i.e., rump) in the first 3-wk period after disbudding. However, when analyzing only disbudded animals over a 9-wk period, calves disbudded at $3 \mathrm{~d}$ of age were more sensitive to pressure applied to their rump than calves disbudded at $35 \mathrm{~d}$ of age on d 28 , 42 , and 56 after disbudding (time since disbudding $\times$ disbudding age: $F_{9,183}=1.97 ; P=0.045$; Figure 8). To determine whether this result was driven by lessdeveloped locomotor ability in the younger calves, we conducted a post hoc analysis to assess the effect of disbudding age on flank sensitivity when calves from both groups were the same age. To do this, we subset the data to only ages when both groups were tested (35 $\mathrm{d}<$ age $<68 \mathrm{~d}$ ). The model included disbudding age as a fixed effect and calf as a random effect. When matching calves by age, the effect of disbudding age was still present, with calves disbudded at $3 \mathrm{~d}$ of age responding at lower thresholds of force than calves disbudded at 35 d of age $\left(3 \mathrm{~d}: 2.81 \pm 0.29 \mathrm{~N} ; 35 \mathrm{~d}: 3.93 \pm 0.29 \mathrm{~N} ; F_{1,22}\right.$ $=7.47 ; P=0.012)$.

\section{Infrared Thermography}

The surface temperature of disbudding wounds did not differ from that of nondisbudded tissue (disbudded: $37.1 \pm 0.51^{\circ} \mathrm{C}$; sham: $37.2 \pm 0.51^{\circ} \mathrm{C} ; F_{1,41}=0.03$; $P=0.859)$. Surface temperature decreased over time, regardless of disbudding (time since disbudding: $F_{5,388}$ $=3.79 ; P=0.002$ ).

\section{Weight}

Calves disbudded or sham-disbudded at $35 \mathrm{~d}$ of age gained over twice as much weight during the week following the procedure than calves disbudded or shamdisbudded at $3 \mathrm{~d}$ of age $(3 \mathrm{~d}: 0.35 \pm 0.06 \mathrm{~kg} / \mathrm{d} ; 35 \mathrm{~d}$ : $\left.0.77 \pm 0.06 \mathrm{~kg} / \mathrm{d} ; F_{1,42}=22.21, P<0.001\right)$. There was no effect of disbudding and no interaction between disbudding and age at the time of procedure on $\mathrm{ADG}$ (disbudded: $0.59 \pm 0.06 \mathrm{~kg} / \mathrm{d}$; sham: $0.52 \pm 0.06 \mathrm{~kg} / \mathrm{d}$; $\left.F_{1,42}<0.60, P>0.444\right)$. Neither the procedure, day relative to the procedure, age at the time of the procedure, nor their 2-way interactions predicted girth circumference ADG at any period during healing. On 
average, girth circumference increased by $0.3 \pm 0.2$ $\mathrm{cm} / \mathrm{d}$ (mean $\pm \mathrm{SD}$ ) during the trial. At 9 wk of age, girth circumference did not differ between calves that had been disbudded at 3 and $35 \mathrm{~d}$ of age $(3 \mathrm{~d}$ : $95 \pm 1$ cm; 35 d: $\left.93 \pm 2 \mathrm{~cm} ; F_{1,21}=1.46, P=0.240\right)$.

\section{DISCUSSION}

Disbudding wounds were sensitive to applied pressure throughout the 9-wk healing period, regardless of the calf's age at the time of the procedure and the type of tissue present in the wound. Calf age at the time of disbudding also did not mediate wound re-epithelialization or weight gain in the following weeks. However, calves disbudded near birth were more sensitive at a site distal to the injury compared with calves disbudded at $35 \mathrm{~d}$ of age, suggesting painful neonatal experiences may have systemic effects on nociceptive pathways.

Hot-iron disbudding wounds took, on average, $9 \mathrm{wk}$ to re-epithelialize. This result is consistent with healing times reported for hot-iron brands, which take at least 10 wk to re-epithelialize in 4- to 7-mo-old beef calves (Tucker et al., 2014a,b). Surprisingly, the necrotic tissue took $3 \mathrm{~d}$ longer to detach when calves were disbudded at $3 \mathrm{~d}$ of age. We had expected the necrotic tissue to separate sooner in younger calves due to the smaller iron diameter. Necrotic tissue is undesirable because it inhibits wound healing and is a medium for bacterial growth; early excision of this tissue accelerates healing in human burn patients (David and Chiu, 2018). In humans, energetic demands can more than double after a severe burn, and nutritional deficits impair healing (Clark et al., 2017). The restricted milk volume fed in the first 2 wk $(<4 \mathrm{~L} / \mathrm{d})$ was likely insufficient to meet basic, let alone these increased, energetic demands. Indeed, dairy calves given free access to milk consume more than twice this amount (Khan et al., 2011a). Calves disbudded at 35 d of age may be better equipped to meet these nutritional requirements due to increased milk rations and solid feed intake, and a more developed digestive tract and thermoregulatory response (Hulbert and Moisa, 2016). Accordingly, ADG was twice as high between 35 and $42 \mathrm{~d}$ than between 3 and $10 \mathrm{~d}$ of age in our study. A similar age pattern in ADG in conventionally fed dairy calves has been reported by Jasper and Weary (2002). The plane of nutrition used in our study confounds the association between disbudding age and wound healing, as milk volume increased with age. Future studies should examine healing in young and old calves that have an elevated (biologically normal) plane of nutrition.

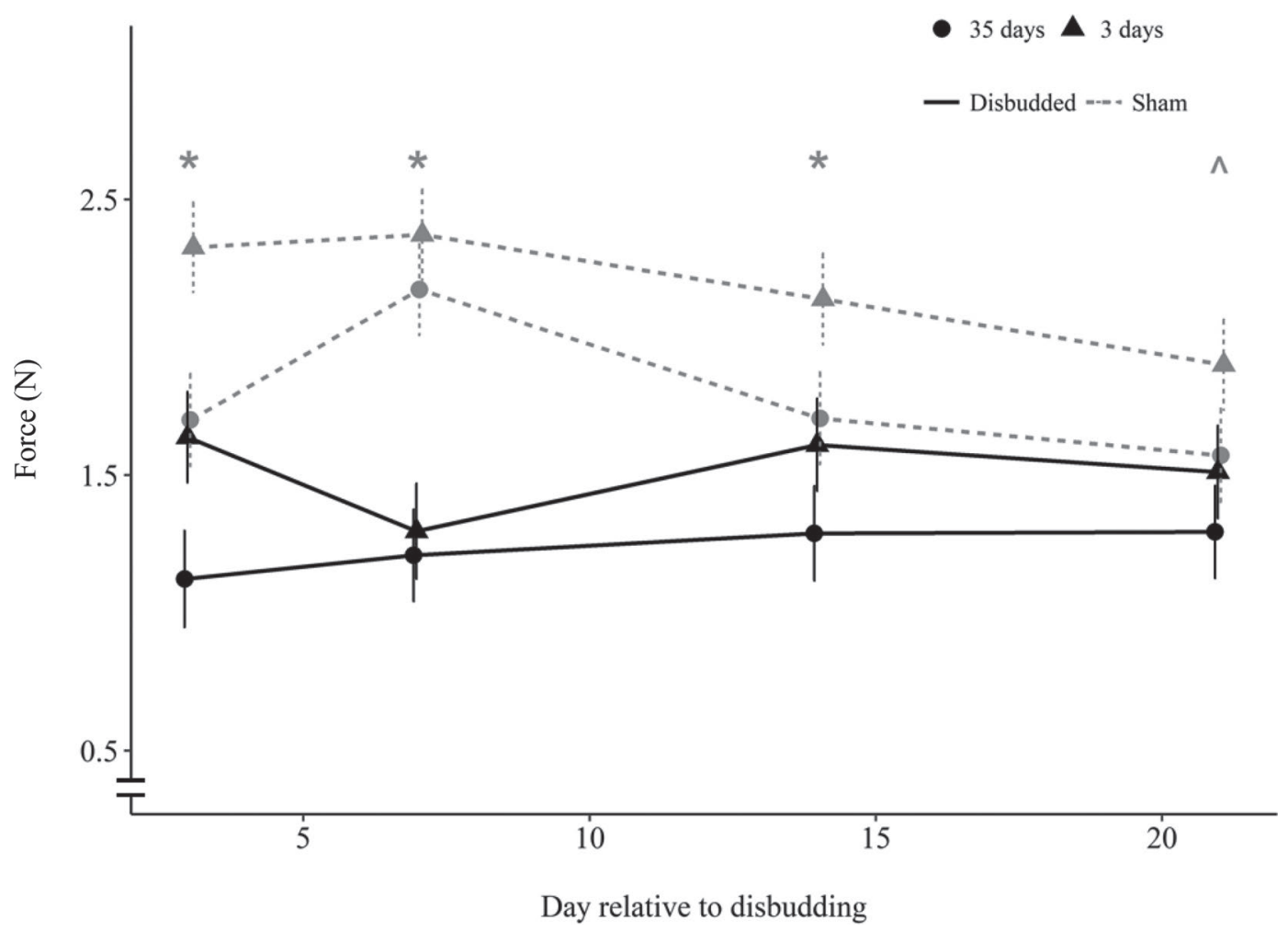

Figure 5. Disbudding wound sensitivity (measured as force, $\mathrm{N}$; least squares means $\pm \mathrm{SE}$ ) for calves disbudded or sham-disbudded at 3 or $35 \mathrm{~d}$ of age. Results are shown in relation to the days since disbudding or sham-disbudding. ${ }^{*} P<0.012 ;{ }^{\wedge} P=0.074$. 
Despite the increased time for the necrotic tissue to detach, the time to re-epithelialize was similar for wounds inflicted at 3 versus $35 \mathrm{~d}$ of age. Older calves experienced stressors in the $5 \mathrm{wk}$ after disbudding (e.g., transition from bottle to bucket-feeding: Veissier et al., 2002; weaning and transition to group-housing: De Paula Vieira et al., 2010); in humans, psychological stress slows healing (Gouin and Kiecolt-Glaser, 2011), and this may be one possibility for why the time to re-epithelialize did not differ between the 2 age groups. Our finding contrasts with a study by Norring et al. (2017), which found that surgical castration incisions closed faster in beef calves castrated at 3 versus $73 \mathrm{~d}$ of age. However, they did find prolonged swelling in the younger calves in the first few weeks after castration, similar to the longer time it took for the necrotic tissue to detach in calves disbudded at an earlier age.

Damaged tissues were almost twice as sensitive as new epithelium, indicating that wounds were painful for, on average, 9 wk. Our finding extends those of other disbudding studies that found wound sensitivity did not return to baseline or control levels by the end of the study period (range 1-7 d: Allen et al., 2013; Mintline et al., 2013; Stock et al., 2015, 2016; Kleinhenz et al., 2017). Our algometer tip had a smaller surface area $\left(13 \mathrm{~mm}^{2}\right)$ than that used by others $\left(79-100 \mathrm{~mm}^{2}\right.$ :
Heinrich et al., 2010; Stock et al., 2016; Kleinhenz et al., 2017; Mirra et al., 2018), thus we needed smaller forces to produce the same amount of pressure (pressure $=$ force/area). When we convert force to pressure, the absolute values and relative decrease in pressure thresholds seen after disbudding in our study agree with others (Heinrich et al., 2010; Stock et al., 2016; Kleinhenz et al., 2017; Mirra et al., 2018). Although decreased thresholds indicate that wounds are painful in response to pressure, it remains unclear whether pain is experienced independent of stimulation, as the mechanisms underlying wound sensitivity and ongoing (nonevoked) pain may be dissociable (Mogil and Crager, 2004). Given our finding that wounds remain sensitive until re-epithelialization is complete, research is needed to address whether and for how long calves experience ongoing, nonevoked pain in the weeks after disbudding.

Disbudding produced similar increases in sensitivity on the head in all calves compared with sham calves, indicating that pain was experienced regardless of age at the time of procedure. This result disagrees with Mirra et al. (2018), who found that only 29-d-old calves, not 6-d-old calves, were more sensitive over a 24-h period after disbudding compared with sham calves. This discrepancy may be due to the $100-\mathrm{mm}^{2}$

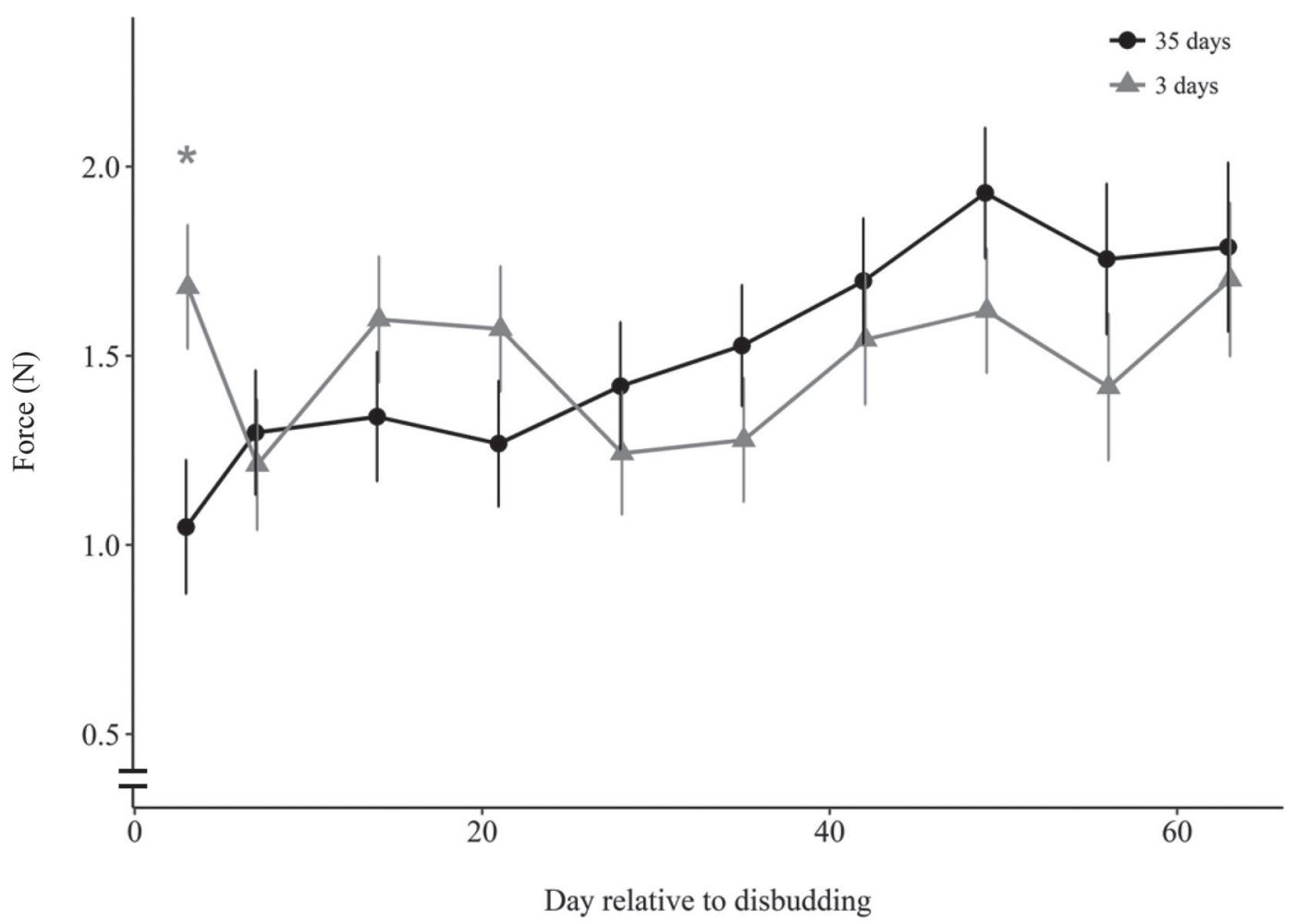

Figure 6. Disbudding wound sensitivity (measured as force, N; least squares means \pm SE) for calves disbudded at 3 or 35 d of age. Results are shown in relation to the days since disbudding. ${ }^{*} P=0.015$. 
algometer tip used in their study. The high forces they recorded $(20-80 \mathrm{~N})$ may have been sufficient to move the younger animals, and thus may not have reflected true thresholds. In agreement with this explanation, they found that both 6 - and 29-d-old disbudded calves were more sensitive than sham calves to von Frey testing, which applies considerably less force $(<2 \mathrm{~N})$ than their pressure algometer.

Sensitivity on the head was greater in 35-d-old calves than in 3-d-old calves only on d 3 after disbudding. Whether this finding reflects decreased pain sensitivity at younger ages or a developmental difference in locomotor ability to move away from a stimulus is unclear. Indeed, we observed increased sensitivity of the head in older calves, independent of disbudding, suggesting that care should be taken when comparing pain thresholds between ages.

In contrast to the sensitivity results on the head, we found that calves disbudded at $3 \mathrm{~d}$ of age were almost 2 times more sensitive to pressure applied to their rump during wk 4, 6 , and 8 after disbudding than calves disbudded at $35 \mathrm{~d}$ of age. The effect persisted when we controlled for age, allowing us to rule out the possibility that this finding was due to developmental differences. This result is consistent with our prediction that younger calves would have a systemic increase in pain sensitivity following disbudding. Painful neonatal experiences in rodents can increase pain responses to subsequent injuries experienced $2 \mathrm{wk}$ later or in adulthood (Walker et al., 2009; Beggs et al., 2012). In rodents, there appears to be a critical neonatal period in which animals are more susceptible to long-term changes in pain sensitivity, as this effect is not seen at older ages (Walker et al., 2016). If this is the case in calves, we should also see increased sensitivity around the wounds in younger animals, but we did not. However, this may have been difficult to observe as calves disbudded at both ages often responded to the lowest force that could be measured by the pressure algometer. It is also unclear why the age difference in rump sensitivity only occurred in some weeks and not others, raising questions about the robustness and welfare implications of this result. Further research is needed to confirm whether persistent increases in pain sensitivity occur after disbudding near birth.

Surface temperature did not differ between disbudded and nondisbudded tissue at any time point in the first 3 wk after the procedure. Consistent with our finding, the surface temperature of hot-iron brands did not differ from unbranded tissue within the same 3-wk

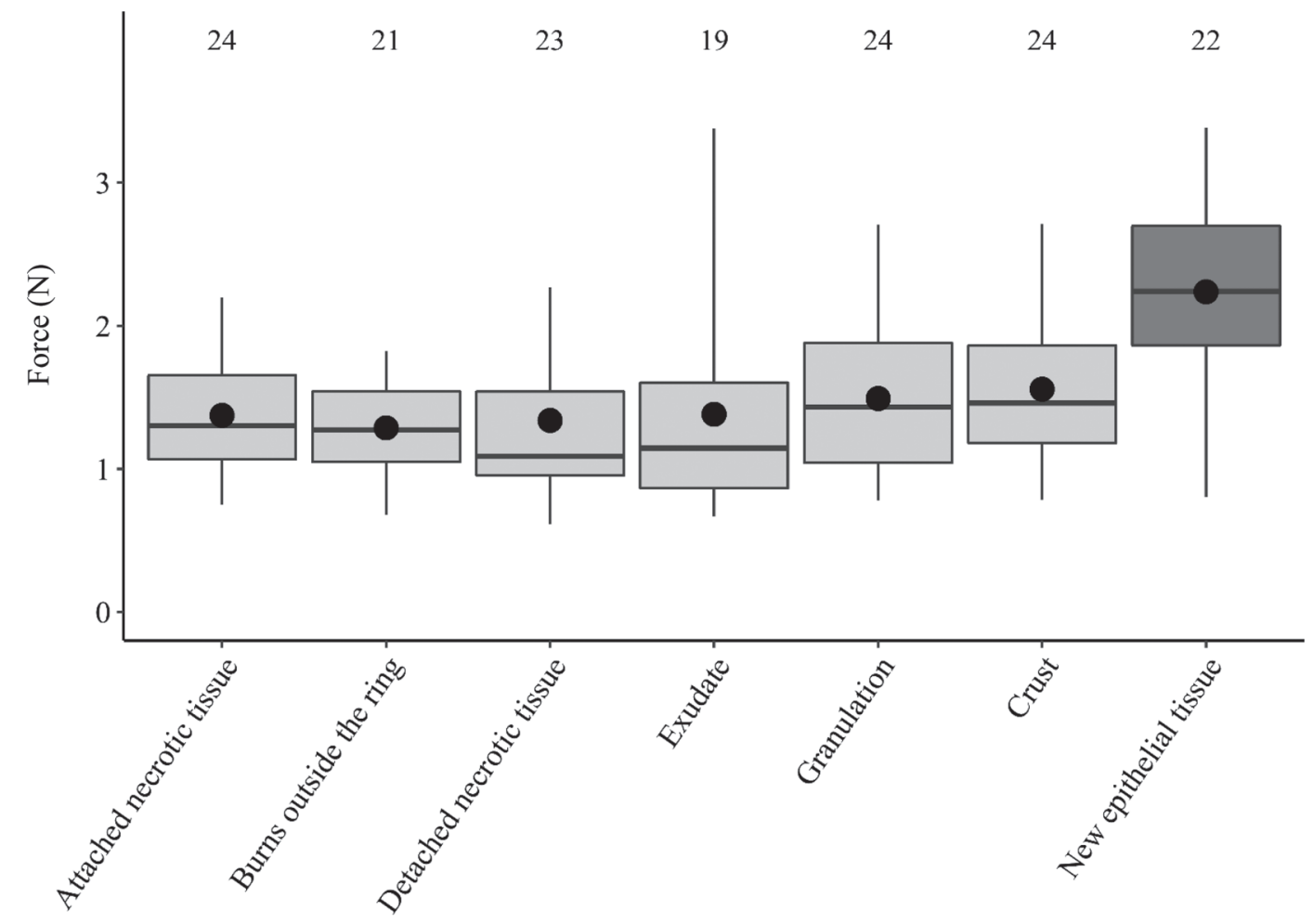

Figure 7. Disbudding wound sensitivity (measured as force, N) for each of the 7 tissue types present in the wound bed. Whiskers indicate the 2nd and 98th percentiles and circles indicate least squares means. The top and bottom of the boxes indicate the 75th and 25th quartiles, respectively. The number of calves in which each tissue was observed (indicated above the box) differed because some tissues were present for longer periods than others. 
window (Tucker et al., 2014b). In addition, Mirra et al. (2018) did not observe a change in wound temperature from baseline over a 24-h period after disbudding. In contrast, thermal imaging has been used successfully in human studies to measure burn severity; superficial burns are warmer than uninjured skin due to inflammation, whereas deeper burns are cooler due to vascular damage (Hardwicke et al., 2013; Paul et al., 2015). It is unclear why thermal imaging in cattle has not been able to detect differences between burns and uninjured skin.

We documented burns of lesser severity around the outside of the necrotic ring in 21 of 24 calves. Others have noted burns around the periphery of hot-iron disbudding wounds in calves (Petrie et al., 1996) and in goats (L. Alvarez, Universidad Nacional Autónoma de México, Mexico City, Mexico, unpublished data). It is unclear how common these burns are after disbudding and whether they are due to skin exposure from clipping the hair.

Disbudding near birth did not improve ADG in the week after the procedure or girth circumference ADG in the 9-wk follow-up period compared with calves disbudded at $35 \mathrm{~d}$ of age, and animals from both age groups had similar girth circumferences at 9 wk of age. This result may be explained by the similar heal- ing rates in both age groups or by a lack of effect of disbudding on growth. In support of the latter interpretation, disbudding did not impair ADG $(\mathrm{kg})$ in the week after the procedure and we saw no differences in girth circumference ADG between disbudded and sham animals. The girth circumference ADG observed in our study $(0.3 \pm 0.2 \mathrm{~cm} / \mathrm{d})$ is similar to what others have reported (Khan et al., 2011b). The lack of a disbudding effect on weight gain agrees with studies on branding, where no long-term changes in weight gain have been detected (Schwartzkopf-Genswein et al., 1997; Tucker et al., 2014b). These results suggest that ADG and girth circumference are not particularly useful for evaluating disbudding outcomes.

To date, welfare concerns surrounding disbudding have focused on the acute pain response. Our findings raise additional concerns about the longer-term consequences of the procedure. As a long-term solution, genetic selection for polled cattle will reduce the need for disbudding (Spurlock et al., 2014). However, until the polled trait becomes widespread, strategies to mitigate pain associated with disbudding are needed to improve calf welfare. To our knowledge, only one study has evaluated strategies to improve healing; Huebner et al. (2017) found that a topical aluminum-based aerosol bandage reduced healing complications during a 3 -wk

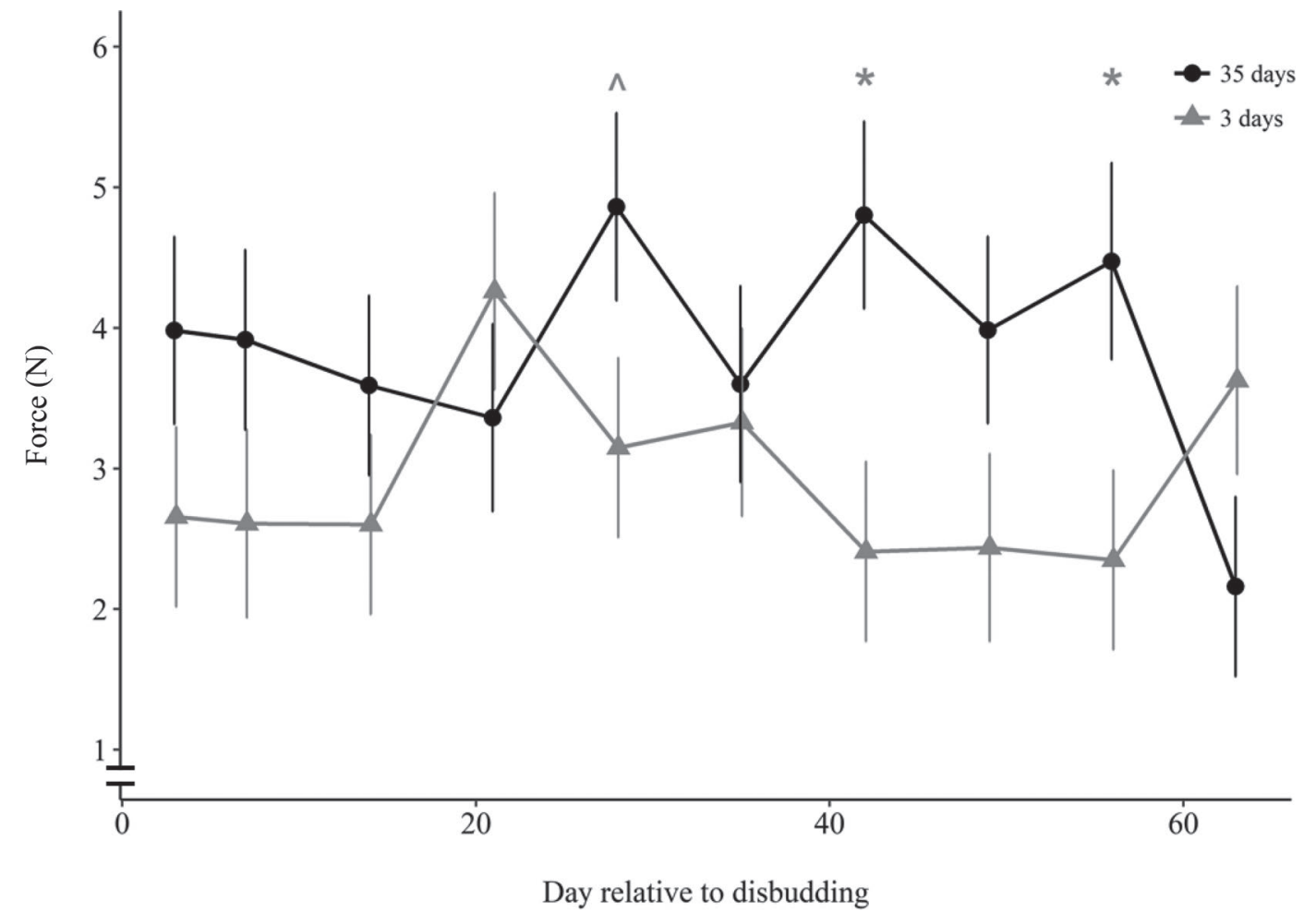

Figure 8. Rump sensitivity (measured as force, N; least squares means \pm SE) for calves disbudded at 3 or 35 d of age. Results are shown in relation to the days since disbudding. ${ }^{*} P \leq 0.035 ;^{\wedge} P=0.077$. 
period after disbudding. Caustic paste disbudding has been suggested as an alternative to hot-iron disbudding. However, potential longer-term consequences of this method (i.e., inflammatory pain, healing time, horn regrowth, injuries from chemical run-off) are unknown and, to date, few studies have found a way to mitigate the acute pain response associated with caustic paste (but see Stilwell et al., 2009; Winder et al., 2017).

\section{CONCLUSIONS}

Hot-iron disbudding wounds take 9 wk to heal and are painful throughout this time, raising concerns about the welfare implications of this practice. Disbudding near birth, at best, does not alter welfare outcomes, and at worst may have a detrimental effect by producing a systemic increase in pain sensitivity.

\section{ACKNOWLEDGMENTS}

We thank University of California Davis Dairy Facility manager Doug Gisi, assistant manager Maria Patino, and the dairy interns for animal care and support. We are grateful to those who assisted with data collection: Emily Bingham, Kelsey Blackston, Victoria Cheng, Natrine Cheuk, Katelyn Devore, Cynthia Echeverria, Katrina Gong, Colleen Leung, Justine Nguyen, Amanda Ormonde, Savanah Vieira, Rechelle Viernes, Megan Wells, Samantha Wong, and Kyra van der Zalm (all affiliated with UC Davis at the time of the study). This study was supported by USDA Multistate Research Project NC1029, and a National Sciences and Engineering Research Council PGS-D, a National Milk Producers Federation Hintz Memorial Scholarship, and a Henry A. Jastro Research Scholarship Award to S. J. J. A. We gratefully acknowledge the infrastructure support of the Department of Animal Science, College of Agricultural and Environmental Sciences, and the UC Davis California Agricultural Experiment Station.

\section{REFERENCES}

Adcock, S. J. J., and C. B. Tucker. 2018. Painful procedures: When and what should we be measuring? Pages 157-198 in Advances in Cattle Welfare. C. B. Tucker, ed. Elsevier, Duxford, UK.

Allen, K. A., J. F. Coetzee, L. N. Edwards-Callaway, H. Glynn, J. Dockweiler, B. KuKanich, C. Wang, E. Fraccaro, M. Jones, and L. Bergamasco. 2013. The effect of timing of oral meloxicam administration on physiological responses in calves after cautery dehorning with local anesthesia. J. Dairy Sci. 96:5194-5205. https://doi.org/ $10.3168 /$ jds.2012-6251.

American Association of Bovine Practitioners. 2014. Castration and dehorning guidelines. Accessed Jan. 6, 2018. http://www .aabp.org/resources/aabp_guidelines/castration_and_dehorning _guidelines_app3.2014_03.17.2014.pdf.

American Veterinary Medical Association. 2018. Castration and dehorning of cattle. Accessed Jan. 6, 2018. https://www.avma.org/ KB/Policies/Pages/Castration-and-Dehorning-of-Cattle.aspx.
Beggs, S., G. Currie, M. W. Salter, M. Fitzgerald, and S. M. Walker. 2012. Priming of adult pain responses by neonatal pain experience: Maintenance by central neuroimmune activity. Brain 135:404-417. https://doi.org/10.1093/brain/awr288.

Boesch, D., A. Steiner, L. Gygax, and M. Stauffacher. 2008. Burdizzo castration of calves less than 1 -week old with and without local anaesthesia: Short-term behavioural responses and plasma cortisol levels. Appl. Anim. Behav. Sci. 114:330-345. https://doi.org/10 .1016/j.applanim.2008.02.010.

Caray, D., A. de Boyer des Roches, S. Frouja, S. Andanson, and I. Veissier. 2015. Hot-iron disbudding: Stress responses and behavior of 1- and 4-week-old calves receiving anti-inflammatory analgesia without or with sedation using xylazine. Livest. Sci. 179:22-28. https://doi.org/10.1016/j.livsci.2015.05.013.

Clark, A., J. Imran, T. Madni, and S. E. Wolf. 2017. Nutrition and metabolism in burn patients. Burns Trauma 5:11. https://doi.org/ 10.1186/s41038-017-0076-x.

Council of Europe. 1988. Recommendation concerning cattle. Accessed Sep. 5, 2016. http://www.coe.int/t/e/legal_affairs/legal _co-operation/biological_safety_and_use_of_animals/farming/ Rec\%20cattle\%20E.asp.

David, J. A., and E. S. Chiu. 2018. Surgical debridement. Pages 3-15 in Interventional Treatment of Wounds: A Modern Approach for Better Outcomes. D. P. Orgill, ed. Springer International Publishing, Cham, Switzerland.

De Paula Vieira, A., M. A. G. von Keyserlingk, and D. M. Weary. 2010. Effects of pair versus single housing on performance and behavior of dairy calves before and after weaning from milk. J. Dairy Sci. 93:3079-3085. https://doi.org/10.3168/jds.2009-2516.

Demling, R. H. 2009. Nutrition, anabolism, and the wound healing process: An overview. Eplasty 9:e9.

Dockweiler, J. C., J. F. Coetzee, L. N. Edwards-Callaway, N. M. Bello, H. D. Glynn, K. A. Allen, M. E. Theurer, M. L. Jones, K. A Miller, and L. Bergamasco. 2013. Effect of castration method on neurohormonal and electroencephalographic stress indicators in Holstein calves of different ages. J. Dairy Sci. 96:4340-4354. https: //doi.org/10.3168/jds.2012-6274.

Gouin, J.-P., and J. K. Kiecolt-Glaser. 2011. The impact of psychological stress on wound healing: Methods and mechanisms. Immunol Allergy Clin. North Am. 31:81-93. https://doi.org/10.1016/j.iac 2010.09.010.

Guesgen, M. J., N. J. Beausoleil, E. O. Minot, M. Stewart, G. Jones, and K. J. Stafford. 2011. The effects of age and sex on pain sensitivity in young lambs. Appl. Anim. Behav. Sci. 135:51-56. https:/ /doi.org/10.1016/j.applanim.2011.09.008.

Hardwicke, J., R. Thomson, A. Bamford, and N. Moiemen. 2013. A pilot evaluation study of high resolution digital thermal imaging in the assessment of burn depth. Burns 39:76-81. https://doi.org/10 .1016/j.burns.2012.03.014.

Heinrich, A., T. F. Duffield, K. D. Lissemore, and S. T. Millman. 2010 The effect of meloxicam on behavior and pain sensitivity of dairy calves following cautery dehorning with a local anesthetic. J. Dairy Sci. 93:2450-2457. https://doi.org/10.3168/jds.2009-2813.

Huebner, K. L., A. K. Kunkel, C. S. McConnel, R. J. Callan, R. P. Dinsmore, and L. S. Caixeta. 2017. Evaluation of horn bud wound healing following cautery disbudding of preweaned dairy calves treated with aluminum-based aerosol bandage. J. Dairy Sci. 100:3922-3929. https://doi.org/10.3168/jds.2016-12192.

Hulbert, L. E., and S. J. Moisa. 2016. Stress, immunity, and the management of calves. J. Dairy Sci. 99:3199-3216. https://doi.org/10 $.3168 /$ jds.2015-10198.

Jasper, J., and D. M. Weary. 2002. Effects of ad libitum milk intake on dairy calves. J. Dairy Sci. 85:3054-3058. https://doi.org/10.3168/ jds.S0022-0302(02)74391-9.

Johnson, C. B., K. J. Stafford, S. P. Sylvester, R. N. Ward, S. Mitchinson, and D. J. Mellor. 2005. Effects of age on the electroencephalographic response to castration in lambs anaesthetised using halothane in oxygen. N. Z. Vet. J. 53:433-437. https://doi.org/10 $.1080 / 00480169.2005 .36589$

Johnson, C. B., S. P. Sylvester, K. J. Stafford, S. L. Mitchinson, R. N Ward, and D. J. Mellor. 2009. Effects of age on the electroencepha- 
lographic response to castration in lambs anaesthetized with halothane in oxygen from birth to 6 weeks old. Vet. Anaesth. Analg. 36:273-279. https://doi.org/10.1111/j.1467-2995.2009.00448.x.

Khan, M. A., D. M. Weary, and M. A. von Keyserlingk. 2011a. Invited review: Effects of milk ration on solid feed intake, weaning, and performance in dairy heifers. J. Dairy Sci. 94:1071-1081. https:// doi.org/10.3168/jds.2010-3733.

Khan, M. A., D. M. Weary, and M. A. G. von Keyserlingk. 2011b. Hay intake improves performance and rumen development of calves fed higher quantities of milk. J. Dairy Sci. 94:3547-3553. https://doi .org/10.3168/jds.2010-3871.

Kleinhenz, M. D., N. K. Van Engen, P. J. Gorden, J. Ji, P. Walsh, and J. F. Coetzee. 2017. Effects of transdermal flunixin meglumine on pain biomarkers at dehorning in calves. J. Anim. Sci. 95:19932000. https://doi.org/10.2527/jas.2016.1138.

Lenth, R. V. 2016. Least squares means: The R package lsmeans. J. Stat. Softw. 69:1-33. https://doi.org/10.18637/jss.v069.i01.

McCracken, L., N. Waran, S. Mitchinson, and C. B. Johnson. 2010. Effect of age at castration on behavioural response to subsequent tail docking in lambs. Vet. Anaesth. Analg. 37:375-381. https:// doi.org/10.1111/j.1467-2995.2010.00547.x.

Mellor, D. J., and K. J. Stafford. 2004. Animal welfare implications of neonatal mortality and morbidity in farm animals. Vet. J. 168:118-133. https://doi.org/10.1016/j.tvjl.2003.08.004.

Mintline, E. M., M. Stewart, A. R. Rogers, N. R. Cox, G. A. Verkerk, J. M. Stookey, J. R. Webster, and C. B. Tucker. 2013. Play behavior as an indicator of animal welfare: Disbudding in dairy calves. Appl. Anim. Behav. Sci. 144:22-30. https://doi.org/10.1016/j .applanim.2012.12.008.

Mirra, A., C. Spadavecchia, R. Bruckmaier, A. Gutzwiller, and D. Casoni. 2018. Acute pain and peripheral sensitization following cautery disbudding in 1- and 4-week-old calves. Physiol. Behav. 184:248-260. https://doi.org/10.1016/j.physbeh.2017.11.031.

Mogil, J. S., and S. E. Crager. 2004. What should we be measuring in behavioral studies of chronic pain in animals? Pain 112:12-15. https://doi.org/10.1016/j.pain.2004.09.028.

National Milk Producers Federation. 2016. FARM Animal Care Reference Manual Version 3.0. Accessed Jan. 6, 2018. http://www .nationaldairyfarm.com/sites/default/files/Version-3-Manual.pdf.

Newsome, T. W., A. D. Mason, and B. A. Pruitt. 1973. Weight loss following thermal injury. Ann. Surg. 178:215-217.

Norring, M., E. M. Mintline, and C. B. Tucker. 2017. The age of surgical castration affects the healing process in beef calves. Transl. Anim. Sci. 1:358-366. https://doi.org/10.2527/tas2017.0044.

Paul, D. W., P. Ghassemi, J. C. Ramella-Roman, N. J. Prindeze, L. T. Moffatt, A. Alkhalil, and J. W. Shupp. 2015. Noninvasive imaging technologies for cutaneous wound assessment: A review. Wound Repair Regen. 23:149-162. https://doi.org/10.1111/wrr.12262.

Petrie, N. J., D. J. Mellor, K. J. Stafford, R. A. Bruce, and R. N. Ward. 1996. Cortisol responses of calves to two methods of disbudding used with or without local anaesthetic. N. Z. Vet. J. 44:9-14.

Pinheiro, J., D. Bates. S. DebRoy, D. Sarkar, and R Core Team. 2017. nlme: Linear and nonlinear mixed effects models. $\mathrm{R}$ package version 3.1-131, http://CRAN.R-project.org/package=nlme.

R Core Team. 2017. R: A language and environment for statistical computing. R Foundation for Statistical Computing, Vienna, Austria.

Schwartzkopf-Genswein, K. S., J. M. Stookey, E. D. Janzen, and J. McKinnon. 1997. Effects of branding on weight gain, antibiotic treatment rates and subsequent handling ease in feedlot cattle. Can. J. Anim. Sci. 77:361-367.

Spurlock, D. M., M. L. Stock, and J. F. Coetzee. 2014. The impact of 3 strategies for incorporating polled genetics into a dairy cattle breeding program on the overall herd genetic merit. J. Dairy Sci. 97:5265-5274. https://doi.org/10.3168/jds.2013-7746.

Stilwell, G., R. C. de Carvalho, M. S. Lima, and D. M. Broom. 2009. Effect of caustic paste disbudding, using local anaesthesia with and without analgesia, on behaviour and cortisol of calves. Appl. Anim. Behav. Sci. 116:35-44. https://doi.org/10.1016/j.applanim 2008.06.008.

Stock, M. L., S. L. Baldridge, D. Griffin, and J. F. Coetzee. 2013. Bovine dehorning: Assessing pain and providing analgesic management. Vet. Clin. North Am. Food Anim. Pract. 29:103-133. https: //doi.org/10.1016/j.cvfa.2012.11.001.

Stock, M. L., L. A. Barth, N. K. Van Engen, S. T. Millman, R. Gehring, C. Wang, E. A. Voris, L. W. Wulf, L. Labeur, W. H. Hsu, and J. F. Coetzee. 2016. Impact of carprofen administration on stress and nociception responses of calves to cautery dehorning. J. Anim. Sci. 94:542-555. https://doi.org/10.2527/jas.2015-9510.

Stock, M. L., S. T. Millman, L. A. Barth, N. K. Van Engen, W. H. Hsu, C. Wang, R. Gehring, R. L. Parsons, and J. F. Coetzee. 2015. The effects of firocoxib on cautery disbudding pain and stress responses in preweaned dairy calves. J. Dairy Sci. 98:6058-6069. https://doi.org/10.3168/jds.2014-8877.

Taddio, A., J. Katz, A. L. Ilersich, and G. Koren. 1997. Effect of neonatal circumcision on pain response during subsequent routine vaccination. Lancet 349:599-603. https://doi.org/10.1016/S0140 -6736(96)10316-0.

Tucker, C. B., E. M. Mintline, J. Banuelos, K. A. Walker, B. Hoar, D. Drake, and D. M. Weary. 2014a. Effect of a cooling gel on pain sensitivity and healing of hot-iron cattle brands. J. Anim. Sci. 92:5666-5673. https://doi.org/10.2527/jas.2014-7860.

Tucker, C. B., E. M. Mintline, J. Banuelos, K. A. Walker, B. Hoar, A. Varga, D. Drake, and D. M. Weary. 2014b. Pain sensitivity and healing of hot-iron cattle brands. J. Anim. Sci. 92:5674-5682. https://doi.org/10.2527/jas.2014-7887.

US Food and Drug Administration. 1994. Animal Medicinal Drug Use Clarification Act (AMDUCA) of 1994. Accessed Jun. 12, 2018. https://www.fda.gov/animalveterinary/ guidancecomplianceenforcement/actsrulesregulations/ucm085377 .htm.

USDA. 2018. Health and Management Practices on U.S. Dairy Operations, 2014. Accessed Jun. 12, 2018. https://www.aphis.usda .gov/animal_health/nahms/dairy/downloads/dairy14/Dairy14 _dr_PartIII.pdf.

Veissier, I., A. M. de Passille, G. Despres, J. Rushen, I. Charpentier, A. R. Ramirez de la Fe, and P. Pradel. 2002. Does nutritive and non-nutritive sucking reduce other oral behaviors and stimulate rest in calves? J. Anim. Sci. 80:2574-2587. https://doi.org/10 .1093 /ansci/80.10.2574.

Walker, S. M., S. Beggs, and M. L. Baccei. 2016. Persistent changes in peripheral and spinal nociceptive processing after early tissue injury. Exp. Neurol. 275:253-260. https://doi.org/10.1016/j.expneurol .2015.06.020.

Walker, S. M., K. K. Tochiki, and M. Fitzgerald. 2009. Hindpaw incision in early life increases the hyperalgesic response to repeat surgical injury: Critical period and dependence on initial afferent activity. Pain 147:99-106. https://doi.org/10.1016/j.pain.2009.08 .017 .

Winder, C. B., S. J. LeBlanc, D. B. Haley, K. D. Lissemore, M. A Godkin, and T. F. Duffield. 2017. Clinical trial of local anesthetic protocols for acute pain associated with caustic paste disbudding in dairy calves. J. Dairy Sci. 100:6429-6441. https://doi.org/10 $.3168 /$ jds.2017-12724. 